\title{
Políticas educacionais com perspectiva de gênero nos governos de Michelle Bachelet e Dilma Rousseff*
}

Recebido: 16.11 .19

Aprovado: 11.12 .20

\author{
Neiva Furlin (Orcid: https://orcid.org/0000-0002-5103-2104)' \\ Programa de Pós-Graduação em Educação, \\ Universidade do Oeste de Santa Catarina (Unoesc), Joçaba, SC, Brasil.
}

Resumo: Nas últimas décadas, as desigualdades de gênero foram reconhecidas como um problema social a ser enfrentado pelos governos nacionais, por meio de políticas públicas com transversalidade de gênero, em todos os setores estatais. O presente artigo tem por objetivo analisar as políticas educacionais com perspectiva de gênero promovidas pelos Estados brasileiro e chileno, no governo de Dilma Rousseff e Michelle Bachelet, identificando avanços, especificidades, desafios e disputas políticas protagonizadas com a emergência de atores reacionários e conservadores. Trata-se de uma pesquisa comparativa de caráter qualitativo, cujos dados são levantados por meio de pesquisa documental e entrevistas com ex-ministras e integrantes de ONGs feministas. Para a análise dos dados, elegemos os referenciais teóricos dos estudos feministas, de gênero e de políticas públicas. Resultados apontam especificidades tanto das disputas na agenda pública quanto das políticas implementadas que estão diretamente vinculadas aos contextos cultural, político e social desses países.

Palavras-chave: Políticas educacionais. Perspectiva de gênero. Democracia.

\section{Gender perspective education policies in Michelle Bachelet and Dilma Rousseff's governments}

\author{
* Pequisa realizada \\ com fomento do \\ Programa Nacional \\ de Pós-Doutorado da \\ Capes. \\ I. Neiva Furlin \\ é professora \\ permanente do \\ Programa de \\ Pós-Graduação \\ em Educação da \\ Universidade do \\ Oeste de Santa \\ Catarina (Unoesc), \\ Santa Catarina, \\ Brasil; pesquisadora \\ do Núcleo de \\ Estudos e Pesquisas \\ em Políticas \\ Educacionais (Nupe) \\ e líder do Grupo de \\ Pesquisa Educação, \\ Políticas Públicas e \\ Cidadania (Geppec). \\ Pós-doutora pela \\ Universidade \\ Estadual de Maringá \\ (2018). \\ <nfurlin@yahoo. \\ com.br>.
}

\begin{abstract}
In recent decades, gender inequalities have been recognized as a social problem to be addressed by national governments through gender-responsive public policies across all state sectors. This study aims to analyze educational policies from the gender perspective supported by the government of Michelle Bachelet and Dilma Rousseff in Chile and Brazil, respectively, identifying advances, specificities, challenges, and political disputes featured in the emergence of reactionary and conservative actors. This is a comparative research of qualitative character, whose data are collected through documentary research and interviews with former ministers and members of Feminist NGOs. The data was analyzed using feminist theory as regards gender and public policy. Results indicate that the specificities of both public agenda disputes and implemented policies are directly linked to the cultural, political, and social contexts of these countries.
\end{abstract}

Key words: Educational policies. Gender perspective. Democracy. 


\section{Questões introdutórias}

partir dos anos de 1970 , as desigualdades de gênero passaram a ser consi-
deradas um problema social, resultado de um processo de reprodução ins-
titucional e cultural. Os Estados nacionais, nas últimas três décadas, têm dado atenção a esse problema, indubitavelmente pressionados por atores sociais, como os organismos internacionais e os movimentos feministas e de mulheres. Dessa relação entre Estado e sociedade surgiram os mecanismos responsáveis pela elaboração, articulação e implementação de políticas públicas com perspectiva de gênero em todos os setores do governo, como maneira de intervenção na realidade sociocultural, visando produzir efeitos culturais, novas práticas e, consequentemente, a redução das desigualdades de gênero, da discriminação sexista e da violência contra as mulheres.

Tanto o Brasil quanto o Chile seguiram a tendência latino-americana das políticas para a igualdade de gênero, em um primeiro momento, centrada na igualdade de oportunidades, depois para a equidade de gênero com base nos direitos, implementadas a partir da estratégia da transversalidade de gênero em todas as políticas do Estado, como foi demonstrado nos estudos de Astelarra (2005) e de Arriagada (2006), sobre a institucionalização das políticas de gênero no contexto latino-americano. Essas políticas resultaram de uma trajetória histórica de mobilizações feministas que se articularam em torno da luta pela democratização e pelos direitos das mulheres.

Débora de Fina Gonzalez (2017; 2018) tem realizado estudos comparativos entre Brasil e Chile, os quais discutem a institucionalização e a implementação de políticas com perspectiva de gênero. A autora evidencia como os organismos estatais atuaram na elaboração, implementação e avaliação das políticas para as mulheres e a importante influência feminista no desencadeamento desse processo, com suas características específicas em cada país, devido às questões de ordem político-conjuntural. Contudo, nesses estudos não se tem encontrado uma comparação da gestão Bachelet e Dilma, em relação à implementação de políticas de gênero no campo educacional.

Portanto, o presente trabalho tem por objetivo analisar as políticas educacionais com perspectiva de gênero promovidas pelos Estados brasileiro e chileno, na gestão de Michelle Bachelet e de Dilma Rousseff, identificando avanços, especificidades, desafios e disputas políticas protagonizadas na arena política, com a emergência de atores reacionários e conservadores.

O interesse em realizar um estudo comparativo entre Brasil e Chile é em razão desses países terem conhecido, no século XXI, a primeira mulher eleita presidente 
da República: Dilma Rousseff e Michelle Bachelet, mulheres que possuem trajetórias que se intercruzam em alguns aspectos. Ambas lutaram pela democracia em seus países; foram presas durante as ditaduras; foram eleitas por dois mandatos ${ }^{1}$ e, com suas especificidades, ambas apresentam uma trajetória comprometida com importantes causas políticas e culturais. Essas experiências parecem conectar-se com suas ações políticas na posição de chefes de Estado quando está em questão a defesa dos direitos das mulheres e a promoção de políticas que promovam a equidade de gênero.

Trata-se de um estudo qualitativo de perspectiva comparativa. Segundo Bertrand Badie e Guy Hermet (1993), o método comparativo permite comparar fenômenos sociais que pertencem à mesma categoria, mesmo se em contextos diferentes, com o intuito de explicar a sua gênese e as suas diferenças de configuração ou de arranjos, considerando a especificidade dos contextos político, social e cultural de cada país. Esses autores alertam que os objetos comparados precisam ter pontos em comum e, ao mesmo tempo, devem se distinguir para que a comparação se torne útil. Acreditamos que a proposta deste estudo - analisar as políticas educacionais com perspectiva de gênero promovidas pelos governos de Bachelet e Dilma - responde a tais critérios.

Os dados foram levantados por meio de fontes secundárias, como pesquisa bibliográfica pautada em artigos temáticos e teses, bem como em fontes primárias, com base em análise documental, como leis, relatórios do Instituto de Pesquisa Econômica Aplicada (Ipea) e da Comissão Econômica para a América Latina e o Caribe (Cepal), Planos de Políticas da Secretaria de Políticas para Mulheres (SPM), no Brasil, e do Serviço Nacional da Mulher (Sernam), no Chile, e entrevistas semiestruturadas com três mulheres que ocuparam a função de ministras do Sernam nos governos de Michelle Bachelet e uma ministra da SPM que atuou no governo de Dilma Rousseff.

A análise comparativa e interpretativa dos dados é realizada segundo os referenciais teóricos que fundamentam as políticas públicas e de gênero. A perspectiva de gênero tem sido fecunda para a compreensão da realidade social e para os processos de produção do conhecimento, mas também tem se constituído como ferramenta importante para a construção de políticas comprometidas com a mudança sociocultural. Segundo as concepções teóricas de autoras feministas, como Teresa de Lauretis (1994) e Joan Scott (1990), as relações de gênero estão imbricadas diretamente com as relações de poder, que hierarquizam e estruturam a sociedade. Para essas autoras, o gênero é uma construção histórica, cultural, relacional e dinâmica sobre o masculino e o feminino, cujas representações acabam por natu-
1. Dilma Rousseff sofreu o processo de impeachment conhecido como golpe parlamentar, na metade do segundo mandato. 
2. Com o termo

"convenções sociais" estamos nos referindo ao conjunto de normas e costumes impostos pela cultura patriarcal. ralizar papéis sexuais e sociais. Certas representações do masculino e do feminino, reproduzidas pela cultura patriarcal, contribuíram para a exclusão das mulheres em espaços públicos, legitimando a opressão e a violência contra as mulheres. E por serem construções históricas, também podem ser desconstruídas por novas representações e práticas culturais, que aqui podem ser pensadas em termos de legislação e de políticas públicas implementadas pelo Estado. A partir da perspectiva de Lauretis, as políticas com perspectiva de gênero podem ser concebidas como tecnologias que produzem novas representações sobre o masculino e o feminino, uma vez que transversalizar a perspectiva de gênero nas políticas educacionais significou o compromisso do Estado com processos de mudanças culturais.

A transversalidade de gênero passou a ser uma exigência da Plataforma de Ação de Beijing, que resultou da IV Conferência Mundial das Mulheres de 1995, para os Estados signatários. Compreende-se a transversalidade de gênero como estratégia de política pública que busca alcançar um objetivo maior: a igualdade entre mulheres e homens e a plena cidadania das mulheres (Bandeira \& Vieira, 2004). Contudo, a igualdade substantiva requer políticas de equidade de gênero, isto é, de um conjunto de processos de ajuste genérico composto pelas ações que reparam as lesões que a desigualdade produziu em relação às mulheres e a outras minorias sociais (Lagarde, 1996).

Ao abordar as políticas com perspectiva de gênero na educação é preciso nos remeter ao paradigma tridimensional de justiça social de Nancy Fraser (2002), que incluiu políticas de redistribuição e de reconhecimento e também a representação política. Para esta autora, é fundamental que as mulheres, como atrizes sociais, estejam representadas na arena política, lugar das decisões acerca das políticas de redistribuição e de reconhecimento, como forma de fazer justiça social às diferentes mulheres que, historicamente, foram privadas do acesso aos bens materiais e simbólicos, por convenções sociais da cultura patriarcal².

Vale ressaltar que a teoria feminista concebe o Estado não somente como um aparato repressivo, mas também como produtor de práticas sociais (Stromquist, 1996), o que reforça a importância da representação política das mulheres em espaços de decisão, como uma dimensão da justiça social, conforme defende Nancy Fraser (2005).

Tanto no Chile quanto no Brasil, a partir do início do século XXI, durante os governos de partidos de centro-esquerda, um número considerado de mulheres feministas adentrou na estrutura estatal, contribuindo de maneira significativa com o avanço na implementação de políticas com perspectivas de gênero, como têm evidenciado os estudos de Claudia Vianna (2018), no caso do Brasil. Esse fenômeno é nomeado 
por Joni Lovenduski (2005) de feminismo de Estado e se refere às ações dos mecanismos institucionais de mulheres, que incluem as demandas e as atrizes do movimento de mulheres no interior do Estado, visando produzir resultados feministas nos processos políticos que objetivam atender às demandas das mulheres, tanto por igualdade de oportunidades como pelo reconhecimento cultural da diferença. Lovenduski (2008) considera que o estabelecimento de agências para as mulheres possibilitou que os movimentos feministas e de mulheres avançassem em suas demandas, modificando as suas formas de atuação, uma vez que essas agências trouxeram a possibilidade de influenciar a agenda. Permitiram o acesso de mulheres nas estruturas do Estado, as quais foram participando do processo político de tomada de decisão e inserindo objetivos feministas nas políticas públicas, como se observa no nosso estudo sobre o campo educacional.

Na visão de Sonia Alvarez (2014), houve um alargamento da sociedade civil, já que se observou uma multiplicação de campos feministas, cujos discursos e práticas se ampliaram para diversos setores paralelos na sociedade civil. Para a autora, os movimentos feministas, e outros movimentos sociais, acabaram se expandindo para além da sociedade civil. Ancorados na sociedade civil, foram se ampliando lateralmente para abarcar diversas instâncias organizativas e, muitas vezes, também se estenderam "verticalmente", em direção à sociedade política, ao Estado e a outros espaços públicos nacionais e transnacionais. Os campos discursivos de ação são muito mais do que meros aglomerados de organizações voltadas para determinada problemática; eles abarcam uma vasta gama de atrizes/atores individuais e coletivos e de lugares sociais, culturais e políticos (Alvarez, 2014: 17-18).

Esses argumentos se aproximam das concepções de Suzana Eróstegui (2008), para quem não existe uma oposição entre sociedade civil e Estado, uma vez que sempre houve vínculos profundos entre classes, agentes ou elites econômicas com o Estado, influenciando as decisões. Fenômeno que também tem se observado com as demandas dos movimentos feministas que foram se tornando ações de Estado. A sociedade civil organizada foi influenciando as ações do Estado, e o próprio Estado tem solicitado a cooperação de ONGs no planejamento e execução de políticas públicas.

Essa relação entre Estado e sociedade civil e o fenômeno que se chamou de Feminismo de Estado foi fundamental para o avanço das políticas com perspectiva de gênero. Cenário que hoje não tem sido o mesmo, com o avanço das forças conservadoras no aparato estatal, em que outros setores vêm influenciando as políticas governamentais. 
Após estas considerações teóricas, convém situar o/a leitor/a acerca da estrutura do presente artigo, que segue cinco pontos: $i$. breve contextualização das políticas de gênero na agenda pública; ii. aspectos da institucionalização dessas políticas no contexto latino-americano, destacando-se o Brasil e o Chile; iii. transversalidade de gênero nas políticas educacionais definidas nos Planos Nacionais; iv. mecanismos criados para garantir a transversalidade de gênero nas políticas; e $v$. desenho das políticas educacionais de gênero na gestão de Michelle Bachelet e Dilma Rousseff, em suas especificidades, avanços, desafios e disputas políticas.

\section{Incorporação das políticas de gênero na agenda pública}

A incorporação das políticas de gênero na agenda pública foi resultado de diferentes fatores, como: compromissos jurídicos dos estados e governos; pressão e mobilização das organizações de mulheres e de movimentos feministas em defesa dos direitos das mulheres, em um cenário social de violência doméstica, de discriminação e de desigualdades de gênero, que exigia uma resposta por parte das instituições estatais (Salazar, 2015).

O marco jurídico e político se consolidou a partir da década de 1990, por meio da realização de importantes convenções e conferências internacionais, onde foram criadas formas de apoio para a resolução dos problemas acerca das questões de gênero. Os processos de organização das conferências internacionais liderados pela ONU, com forte protagonismo e articulação transnacional dos movimentos feministas e de mulheres, foram fundamentais para definir pontos comuns de uma agenda política e para pressionar os governos nacionais a adotarem medidas políticas e jurídicas de promoção da igualdade de gênero e dos direitos das mulheres, o que corrobora com as perspectivas de Eróstegui (2008), de que os vínculos profundos entre Estado e a sociedade civil sempre influenciam as decisões estatais.

Essa trajetória tem como marco significativo a década de 1970, declarada pela ONU como a Década das Mulheres, caracterizada pela efervescência dos movimentos sociais de mulheres e feministas e pelo fortalecimento da ideia sobre a necessidade de um mecanismo, na arena estatal, que fosse orientado para elaborar políticas públicas. Tal proposição se fortaleceu com os documentos que resultaram das sucessivas Conferências Mundiais da ONU sobre os direitos humanos das mulheres e da Convenção para Eliminação de Todas as Formas de Discriminação Contra a Mulher (Cedaw), de 1979, em vigor desde 1981, primeiro tratado internacional a abordar os direitos humanos da mulher (Bandeira \& Vieira, 2004). 
Os países signatários da Plataforma de Ação, que resultou da IV Conferência Mundial das Mulheres, realizada em Beijing, em 1995, e da Cedaw³ ${ }^{3}$ comprometeram-se em assegurar os direitos das mulheres com a adoção de medidas legislativas, judiciais e administrativas, oferecendo relatórios sobre os avanços de sua aplicação. A Plataforma de Ação apontou as 12 preocupações prioritárias para a ação dos Estados ${ }^{4}$, propondo aos governos a criação de mecanismos estatais voltados para a redução das desigualdades de gênero, em todas as dimensões sociais.

De acordo com Maria Luiza Viotti (1995: 149), a Plataforma de Ação se constitui "um guia abrangente para orientar governos e sociedade no aperfeiçoamento do marco legal, na formulação de políticas e na implementação de programas para promover a igualdade de gênero e evitar a discriminação." Cabe destacar que a Plataforma de Ação de Pequim consagrou três inovações que apresentam potencial transformador na luta pela promoção da situação e dos direitos da mulher: o conceito de gênero, a noção de empoderamento e o enfoque da transversalidade.

Nesse sentido, a IV Conferência Mundial é considerada um marco histórico por duas razões: primeiro, por introduzir a perspectiva de gênero na explicação das desigualdades sociais entre mulheres e homens; segundo por impulsionar as políticas públicas para a igualdade, com a incorporação do enfoque de gênero. Assim, a Plataforma de Ação teve três importantes consequências:

i. o fortalecimento dos mecanismos nacionais para melhorar a vida das mulheres;

ii. o desenvolvimento das primeiras políticas públicas de igualdade;

iii. o impulso da transversalidade de gênero, como estratégia de política pública (Salazar, 2015).

A Plataforma de Ação de Beijing se tornou um imperativo de ação para os governos, no sentido de integrar a perspectiva de gênero na legislação, nas políticas públicas, nos programas e projetos, com o compromisso de verificar, antes de sua implementação, os possíveis efeitos na vida das mulheres e homens (Bandeira \& Vieira, 2004).

\section{A Institucionalização das políticas de gênero no contexto latino-americano}

Na América Latina, a institucionalização da perspectiva de gênero nas políticas públicas aparece vinculada ao cenário internacional, cujo processo se iniciou na década de 1970 e se consolidou nos anos 1980. O reconhecimento das desigualdades de
3. A Cedaw contempla as seguintes questões: a pobreza como violação aos direitos humanos; o direito à educação; o direito à participação da vida política o direito de ter acesso às mesmas oportunidades que os homens na esfera do trabalho; o direito da não discriminação na esfera da saúde; o direito de viver uma vida livre e sem violência (Salazar, 2015).

4. E uma dessas preocupações é a desigualdade no acesso à educação e à capacitação. Para conhecer as outras 11 preocupações, consultar Maria Luiza viotti (1995). 
gênero como problema público aparece condicionado à ordem econômica, política, legal e institucional, de modo que as desigualdades de gênero e de etnia passaram a ser consideradas inconcebíveis em uma sociedade democrática, que precisava criar condições para a justiça social (Arriagada, 2006).

Nos anos 1990, a perspectiva de gênero foi se institucionalizando por meio da criação de mecanismos estatais, isso, em parte, pelo avanço dos processos políticos, que teve a participação de diversos atores/atrizes do setor público e de organismos não governamentais. Tratava-se de um contexto de restabelecimento da democracia em países da América Latina, em que as lutas contra as ditaduras militares fortaleceram os movimentos sociais, vislumbrando espaços de participação democrática na orientação das ações e das políticas estatais. Assim, sobretudo nos países do Cone Sul, os processos de redemocratização nacional representaram a oportunidade para que as demandas dos movimentos feministas e de mulheres fossem incluídas nas agendas governamentais (Gonzalez, 2018; Arriagada, 2006). É nesse cenário político nacional de pós-ditadura e de ascensão de governos democráticos, em que houve o envolvimento de campanhas com forte pressão dos grupos de mulheres, que os mecanismos encarregados pelos temas de gênero foram criados (Gusmán, 2005).

Nesse contexto, a relação dos feminismos com o Estado foi se transformando no continente latino-americano. Tornou-se possível o diálogo e a negociação com movimentos sociais e partidos de esquerda e com outras instituições, criando-se canais de interlocução com o Estado, a partir de novas formas de organização feminista, que se originaram dos processos crescentes de institucionalização e profissionalização de organizações feministas, criadas, sobretudo, para intervir nas organizações internacionais e regionais, impulsionadas pelo acordo da Plataforma de Ação de Beijing (Matos \& Paradis, 2013).

Os Mecanismos Institucionais de Políticas para as Mulheres (MIPMs) se constituíram com o objetivo de promover a igualdade e a equidade de gênero por meio da articulação e implementação de políticas públicas com transversalidade de gênero em todas as esferas políticas e níveis de atuação do governo, conforme as recomendações da Plataforma de Ação de Beijing.

\section{Os Mecanismos Institucionais de Políticas} para as Mulheres no Brasil e Chile

No período da ditadura, tanto no Brasil quanto no Chile, os movimentos feministas e de mulheres se fortaleceram exercendo um importante papel de resistência, conjugando a luta em favor da democracia com a luta por melhores condições de 
vida para as mulheres. A luta reivindicatória ocorreu em movimentos sociais independentes e dentro dos partidos de esquerda, que faziam oposição à ditadura. Isso abriu um "caminho para a construção de uma agenda compartilhada com o Estado, processo que não esteve isento de confrontações, tensões e até mesmo de fracassos" (Cepal, 2011: 46).

Ao analisar o caso Brasil-Chile, no que diz respeito à reivindicação dos mecanismos estatais de políticas públicas, é evidente a importância da pressão tanto das mobilizações dos movimentos sociais autônomos como do Feminismo de Estado, no sentido proposto por Lovenduski (2005). Contudo, no Chile, depois da ditadura, houve a desmobilização dos movimentos sociais. A luta feminista por direitos e por políticas públicas ocorreu no interior dos partidos de esquerda, nas ONGs e em Centros de Estudos Feministas e de Gênero no espaço das universidades. Desse modo, a força da ação política do Feminismo de Estado foi um fator importante para a criação do Sernam, em $1991^{5}$, em um contexto de desarticulação dos movimentos populares. No Brasil, a luta feminista se fortaleceu tanto nos partidos de esquerda como nos movimentos sociais e sindicatos. Assim, a conquista do Conselho Nacional de Direitos das Mulheres (CNDM), em 1985, e, posteriormente, a Secretaria de Políticas para Mulheres (SPM), em 2003, contou com a força conjugada das duas práticas de ação política. Evidentemente, essa particularidade está diretamente vinculada às especificidades dos contextos histórico, social e político de cada país.

Se os Mecanismos Institucionais são ferramentas importantes para a promoção e implementação de políticas, que visam à justiça social com perspectiva de gênero, é preciso concordar com as teóricas do Feminismo de Estado que a presença das muIheres feministas no interior do Estado traz resultados mais positivos nos processos políticos. O mesmo podemos afirmar em relação aos argumentos de Nancy Fraser (2005) a respeito da importância de as mulheres estarem representadas na esfera da política, não apenas para visibilizar um novo sujeito social e político, mas como condição necessária para fazer justiça social às diferentes mulheres que, historicamente, foram privadas do acesso aos bens materiais e simbólicos.

\section{Planos Nacionais de Políticas para as Mulheres e a transversalidade de gênero na educação}

Os Planos Nacionais de Políticas para as Mulheres (PNPMs) se constituíram como instrumento, utilizado pelo Sernam e pela SPM, para promover políticas transversais para a igualdade de gênero, considerando as 12 áreas de preocupação prioritárias identificadas pela Plataforma de Ação de Beijing, de 1995, dentre elas, a educação. Em outras palavras, são instrumentos de política pública que fortalecem
5. Em 2015, com a criação do Ministério da Mulher e Equidade de Gênero, o Sernam foi transformado em um serviço do Ministério, sendo responsável pela articulação e implementação das políticas com perspectiva de gênero. 
6. A construção dos PNPMs foi precedida pela realização de fóruns, conferências municipais, estaduais e nacional, com a participação de atores estatais e representantes de movimentos e de organizações da sociedade civil. a institucionalidade e a transversalidade de gênero nas ações destinadas a melhorar as condições de vida das mulheres.

Vale ressaltar que no Chile a elaboração dos planos de políticas seguiu um critério mais técnico, ou seja, foi produzido por atores estatais partidários e contratação de ONGs especializadas. Já no Brasil houve um amplo processo participativo, com

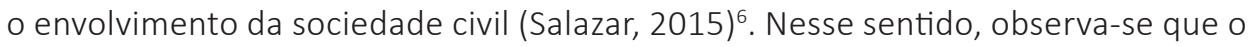
modelo adotado em cada país expressa as relações entre sociedade civil e Estado, que se estruturaram no processo de redemocratização desses países (Furlin, 2020). Praticamente todos os Planos Nacionais de Políticas para Mulheres do Brasil e os Planos para a Igualdade do Chile projetam políticas educacionais com perspectiva de gênero, seja em um eixo específico de ação ou perpassando outros eixos. No Quadro 1 evidenciamos como a educação aparece nos eixos temáticos dos Planos de Políticas dos mecanismos nacionais responsáveis pela promoção, articulação e implementação de políticas para a igualdade/equidade de gênero.

É importante assinalar que no Chile, Bachelet, em seus dois mandatos, assumiu uma Agenda de Gênero como parte do programa de governo, comprometendo diretamente todos os setores do governo na promoção e na implementação de políticas transversais de gênero.

Tanto o Chile quanto o Brasil são signatários dos tratados internacionais, de modo que dar prioridade à educação como um dos espaços para se construir uma cultura

\section{QUADRO 1}

EIXOS ESTRATÉGICOS PARA POLÍTICAS EDUCACIONAIS nos Planos nacionais para as Mulheres/Igualdade de GÊNERo

\begin{tabular}{|c|c|c|c|c|}
\hline Países & Planos & Eixo sobre a educação & $\begin{array}{l}\text { Prioridades/ } \\
\text { objetivos }\end{array}$ & $\begin{array}{l}\text { Ações/ } \\
\text { diretrizes }\end{array}$ \\
\hline \multirow{3}{*}{$\frac{\varrho}{\underline{\underline{U}}}$} & $\begin{array}{c}\text { Plano } \\
1992-1999\end{array}$ & $\begin{array}{l}\text { Participação equitativa de homens e mulheres nos } \\
\text { processos educativos, produção e transmissão de } \\
\text { conhecimento. }\end{array}$ & 8 objetivos & 31 ações \\
\hline & $\begin{array}{l}\text { Plano } \\
2000-2010\end{array}$ & $\begin{array}{l}\text { Sem um eixo especifico, mas com ações em outros eixos, } \\
\text { sobretudo no de "uma cultura de igualdade". }\end{array}$ & 4 objetivos & 18 diretrizes \\
\hline & $\begin{array}{c}\text { Plano } \\
2010-2020\end{array}$ & $\begin{array}{l}\text { Sem um eixo específico, mas com ações em outros } \\
\text { eixos, sobretudo no de "Autonomia na sexualidade e nas } \\
\text { decisões reprodutivas" e no "As meninas e os meninos: } \\
\text { um ponto de partida para igualdade". }\end{array}$ & 4 objetivos & 9 diretrizes \\
\hline \multirow{3}{*}{$\overline{\bar{n}}$} & $\begin{array}{c}\text { Plano } \\
2004-2007\end{array}$ & Educação inclusiva não sexista. & $\begin{array}{l}5 \text { objetivos e } 5 \\
\text { prioridades }\end{array}$ & 31 ações \\
\hline & $\begin{array}{c}\text { Plano } \\
2008-2011\end{array}$ & $\begin{array}{l}\text { Educação inclusiva não sexista, não racista, não } \\
\text { homofóbica e não lesbofóbica. }\end{array}$ & $\begin{array}{l}6 \text { objetivos e } 6 \\
\text { prioridades }\end{array}$ & 37 ações \\
\hline & $\begin{array}{c}\text { Plano } \\
2013-2015\end{array}$ & $\begin{array}{l}\text { Educação para a Igualdade e Cidadania e com ações } \\
\text { também em outros Eixos. }\end{array}$ & $\begin{array}{l}6 \text { objetivos e } 6 \\
\text { linhas de ação }\end{array}$ & 61 ações \\
\hline
\end{tabular}

Fonte: Elaboração própria com base nos Planos Nacionais do Sernam e SPM. 
fundada na igualdade e equidade de gênero, no que diz respeito às diversidades e no combate a todas as formas de discriminação social, torna-se uma estratégia necessária para o desenvolvimento social e econômico, para fazer acontecer a justiça de gênero e fortalecer as democracias modernas, como também enfatizado nos estudos de Salazar (2015).

O Quadro 1 evidencia que os dois países se comprometeram em promover políticas educacionais com perspectiva de gênero. No caso do Brasil, embora os planos apresentem eixos específicos para a educação, outros eixos, como, por exemplo, o que trata o enfrentamento da violência, também definem ações educativas que responsabilizam o Ministério da Educação por sua implementação.

Os planos dos dois países apresentam uma variedade de ações para o campo educacional, como: inserção da perspectiva de gênero nas Diretrizes Curriculares; formação de professores com enfoque em gênero; investigação sobre as desigualdades; eliminação das marcas sexistas na educação; implantação de práticas de igualdade de gênero; combate à discriminação e à homofobia, entre outras. Contudo, vale enfatizar que um bom plano não é suficiente se não houver vontade política e mecanismos que garantam a implementação da transversalidade de gênero nas políticas públicas.

\section{Mecanismos para garantir}

a transversalidade de gênero nas políticas públicas

Para garantir a transversalidade de gênero em todas as áreas de ação do governo, foram criados outros organismos específicos. No Chile, criou-se o Conselho de Ministros para a Igualdade em 2002, que funcionava articulado com os Compromissos Ministeriais e o Sistema de Gênero no Programa de Melhoramento para a Gestão (PMG). No primeiro governo de Bachelet se implantou uma unidade/comitê de gênero em cada ministério, com uma assessora especialista na área específica do ministério e em gênero, cuja ação foi ampliada e fortalecida no segundo mandato de Bachelet ${ }^{7}$.

No Brasil, em 2005, foi criado o Comitê de Articulação e Monitoramento do Plano Nacional de Políticas para as Mulheres, constituído por agentes do governo e representantes da sociedade civil, membros do Conselho Nacional dos Direitos da Mulher (CNDM). O Comitê participava da elaboração dos Planos de Políticas para Mulheres, no qual se definiam as ações a serem implementadas pelos ministérios ou setores do governo. A partir do segundo PNPM, o conceito de gênero foi inserido no Plano Plurianual de Ação do Governo e, posteriormente, foram criados Co- 
8. Vale mencionar que as entrevistadas consentiram, por meio de documento assinado, revelar seus nomes em artigos científicos, uma vez que seus relatos trataram de temas públicos.

9. Esta tensão será tratada no último ponto deste artigo. mitês de Gênero nos ministérios com a função de formular e monitorar as políticas com perspectiva de gênero, acompanhando a execução e a avaliação das ações do PNPM. Até o final do governo Lula, os comitês eram criados voluntariamente pelas mulheres dos respectivos ministérios. Segundo a ex-ministra, Eleonora Menicucci $^{8}$, no governo de Dilma eles foram institucionalizados por meio de portaria ministerial, sendo coordenados pela SPM. No Ministério da Educação, o Comitê de Gênero foi criado em 9 de setembro de 2015, com caráter consultivo, pela Portaria n. 915/2015, tendo a função de contribuir na formulação e avaliação de política, garantindo a transversalidade de gênero em todas as políticas. De acordo com Toni Reis e Edla Eggert (2017), depois de 12 dias de sua criação, o Comitê de Gênero foi extinto e substituído por um Comitê de Combate à Discriminação, de acordo com o que se estabeleceu no Plano Nacional de Educação ${ }^{9}$. Isto é, a palavra gênero foi eliminada da Portaria pela forte pressão à Presidência da República, por parte dos deputados da ala conservadora.

Nota-se que, em ambos os países, os mecanismos para garantir a transversalidade de gênero nas políticas são distintos. No Brasil, eles envolvem a participação da sociedade civil no controle e monitoramento das políticas, enquanto no Chile eles são puramente estatais. Dentro de suas especificidades, esses países buscam cumprir as orientações da Plataforma de Ação de Beijing de 1995, adotando a transversalidade de gênero como estratégica política nas ações de todas as esferas do governo (Furlin, 2020).

\section{O desenho das políticas educacionais de gênero na gestão de Michelle Bachelet e Dilma Rousseff}

Após essas considerações gerais, que permitem compreender aspectos do processo de institucionalização da transversalidade de gênero nas políticas públicas, passamos a abordar as políticas educacionais com perspectiva de gênero que foram implementadas nas gestões de Dilma Rousseff e de Michelle Bachelet. Para a análise comparativa, consideramos as proposições de Badie e Hermet (1993), ou seja, buscamos comparar no intuito de compreender as especificidades e aproximações de um mesmo fenômeno social, inserido em um contexto social, político e cultural distinto, bem como observar as particularidades históricas que permitem o afastamento das tendências universalistas etnocêntricas.

Segundo os dados levantados em entrevista, as políticas transversais de gênero para a educação, no Chile, tiveram maior impacto no segundo mandato de Bachelet, com a reforma educacional, que objetivou garantir a gratuidade na educação pública e proibir a finalidade lucrativa com o serviço de educação das instituições 
privadas. Essa reforma foi considerada uma das mais importantes realizadas no segundo mandato de Bachelet. Vale destacar que no Chile a educação gratuita não existe como direito universal. A gratuidade na educação pública ${ }^{10}$ obedece a princípios da economia neoliberal, ou seja, é focalizada para as classes de baixa renda, cuja seleção obedece a critérios acadêmicos e nível de renda.

De acordo com a Plataforma de Ação de Beijing, uma das preocupações dos Estados nacionais era enfrentar o crescimento da pobreza feminina e, para isso, os governos nacionais precisavam proporcionar políticas para garantir o acesso das mulheres e a sua permanência nas instituições educativas. Nesse sentido, os relatos das entrevistas apontam que a gratuidade na educação pública causou impacto positivo para as mulheres mais pobres, inclusive chefas do lar, porque mais de $50 \%$ das matrículas na educação superior gratuita têm sido de mulheres. A reforma, mesmo sem a profundidade esperada, propôs a inclusão de gênero nos currículos e na formação de professores, como um dos temas fundamentais para se construir uma sociedade democrática com igualdade de gênero.

Como se visualiza no Quadro 2, a reforma educacional proporcionou avanços em diferentes áreas ${ }^{11}$, tais como:

i. incorporação da perspectiva de gênero nas bases curriculares da educação infantil e elaboração de um Caderno de Orientação Pedagógica em relação aos conteúdos e metodologias a serem desenvolvidos na educação infantil;

ii. cursos presenciais e on-line com a temática de gênero para a formação de professores;

iii. elaboração de material contra o assédio sexual, distribuído nas instituições de ensino superior e publicado na Internet;

iv. inclusão da abordagem de gênero nos instrumentos de gestão escolar;

v. formação de avaliadores na perspectiva de gênero.

Assim, a inclusão de conteúdos de gênero no currículo escolar, na formação de professores e de gestores, constitui-se, no sentido de Teresa de Lauretis (1994), uma tecnologia significativa para produzir mudanças culturais nas relações de gênero. Isso porque permite mudar as representações socioculturais sobre comportamentos, funções e lugares destinados ao universo masculino e feminino.
10. Vale enfatizar que a concepção de educação pública no Chile tem outro sentido, por exemplo, no ensino superior

o Chile sempre teve educação pública, mas paga. Diferentemente do Brasil, a educação no Chile se divide em pública, particular e particular subvencionada.

11. Dados do relatório final do MMyEG (Chile, 2018), sobre o cumprimento das medidas de gênero do programa de governo de Bachelet. 
Ainda no que se refere à educação, o governo de Bachelet fortaleceu o programa de criação de berçários nos estabelecimentos educacionais para assegurar a permanência de mães adolescentes na escola e emitiu circulares normativas para proibir a exclusão e a discriminação de crianças LGBTs em ambientes escolares. Essa ação, como política de reconhecimento, segundo Fraser (2005), é fundamental quando se objetiva construir uma sociedade plural e democrática, assentada no respeito aos direitos humanos. Nessas medidas, observa-se concretamente como as demandas do feminismo se transformam em agenda de Estado, o que evidencia a força do Feminismo de Estado ou da sociedade civil alargada, no sentido de Alvarez (2014).

Segundo o relato da ex-ministra Claudia Pascual Grau, uma das atividades do Programa Bem Viver da Sexualidade foi a promoção de oficinas de formação para adolescentes sobre a vivência saudável da sexualidade e foi estabelecida uma estratégia para a educação em sexualidade, afetividade e gênero, em parceria entre os Ministérios da Mulher e Equidade de Gênero, da Saúde e da Educação. Como resultado desse processo, no final do governo de Bachelet foi entregue para todas as escolas públicas um kit com documentos específicos, como: orientações para implementar um programa de formação em sexualidade, afetividade e gênero; orientações para a inclusão de pessoas lesbianas, gays, bissexuais, trans e intersex no sistema educativo do Chile; orientações para a elaboração de um protocolo de atuação diante de maltrato, assédio, abuso sexual e estupro em estabelecimentos educacionais; orientação para o enfoque de gênero nos instrumentos de Gestão Escolar; orientações para promover espaços de participação saudável de convivência escolar; documentos de orientações técnicas para implantar um modelos de gestão intersetorial de aulas de bem-estar; informações sobre o Programa Bem Viver da Sexualidade e Reprodução (Chile, 2018). Indubitavelmente, essas ações tiveram maior efetividade porque no governo de Bachelet foram abertos mais espaços para a presença e a atuação de mulheres nas estruturas do Estado, o que, segundo Lovenduski (2005), produz resultados feministas nos processos políticos e um impacto social positivo para a vida das mulheres e, aqui, também, para sujeitos que não se incluem nos padrões da heterossexualidade.

Já o governo de Dilma, como se observa no Quadro 2, deu continuidade a dois importantes programas do governo de Luís Inácio Lula da Silva. O primeiro foi o MuIher e Ciência, com três áreas de atuação de grande envergadura, tendo como objetivos: incentivar as pesquisas científicas na área dos estudos de gênero; estimular a produção científica na graduação e pós-graduação na área de gênero e feminismos; aprofundar temas e projetos para a igualdade de gênero nas escolas de ensino médio e apoiar núcleos de estudos, agências de fomento, revistas com a temática dos Estudos de Gênero e Feminismos. O programa prioriza claramente a transversalida- 


\begin{tabular}{|c|c|c|}
\hline Governo & Políticas & Especificações \\
\hline \multirow[t]{3}{*}{ 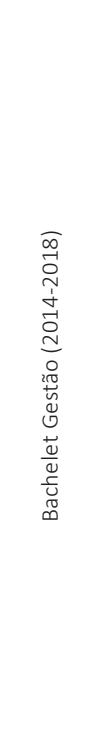 } & $\begin{array}{l}\text { A Reforma Educacional e a inclusão de conteúdos de } \\
\text { gênero no currículo e na formação dos professores }\end{array}$ & $\begin{array}{l}\text { A política de gratuidade na educação "impactou positivamente as mulheres, } \\
\text { pois elas passaram a representar mais de } 50 \% \text { das matrículas no ensino } \\
\text { superior" (Claudia Pascual Grau). } \\
\text { Houve avanços na incorporação de gênero nas bases curriculares na } \\
\text { educação infantil e elaboração do Caderno de Orientação Pedagógica para } \\
\text { incorporar conteúdo e metodologias da perspectiva de gênero na educação } \\
\text { infantil. } \\
\text { Realizaram-se cursos presenciais e on-line com perspectivas de gênero na } \\
\text { educação para os professores. } \\
\text { Elaboração de material contra o assédio sexual no ensino superior, publicado } \\
\text { na Internet e distribuído em todas as instituições de ensino superior. } \\
\text { Inclusão da Abordagem de Gênero nos Instrumentos de Gestão Escolar e } \\
\text { realização da formação de avaliadores com perspectiva de gênero. }\end{array}$ \\
\hline & $\begin{array}{l}\text { Diretrizes e circulares normativas para a não } \\
\text { exclusão de crianças LGBTs dos ambientes escolares }\end{array}$ & $\begin{array}{l}\text { Circular n. } 0768 \text { da Superintendência de Educação sobre direitos de meninas, } \\
\text { meninos e estudantes trans no campo da educação. } \\
\text { Diretrizes para a Inclusão de Pessoas LGTBI no Sistema Escolar. }\end{array}$ \\
\hline & Educação sexual e humanista na instituição escolar & $\begin{array}{l}\text { Construção de uma estratégia para a educação em sexualidade, afetividade } \\
\text { e gênero, envolvendo ministérios afins. No final do governo de Bachelet, foi } \\
\text { entregue para todas as escolas públicas um Kit com documentos específicos } \\
\text { de orientação. }\end{array}$ \\
\hline \multirow{7}{*}{ 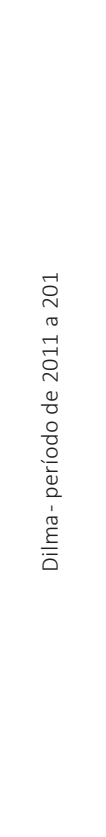 } & $\begin{array}{l}\text { Continuidade do Programa Mulher e Ciência - } \\
\text { promoção da equidade de gênero na ciência }\end{array}$ & $\begin{array}{l}\text { Três áreas de atuação: Edital Relações de gênero, mulheres e feminismos; } \\
\text { Prêmio construindo igualdade de gênero; Encontro nacional de núcleos e } \\
\text { grupos de pesquisa. }\end{array}$ \\
\hline & $\begin{array}{l}\text { Continuidade do Programa Gênero e Diversidades } \\
\text { na Escola - formação para professores/as }\end{array}$ & $\begin{array}{l}\text { Combate às atitudes e comportamentos preconceituosos em relação a } \\
\text { gênero, raça e às diversas orientações sexuais. }\end{array}$ \\
\hline & $\begin{array}{l}\text { Kit, Brasil sem Homofobia - material didático- } \\
\text { pedagógico voltado para combater a homofobia nas } \\
\text { instituições educativas }\end{array}$ & $\begin{array}{l}\text { Foco de tensões com políticos conservadores e fundamentalistas. Dilma, } \\
\text { pressionada pela bancada religiosa, vetou a distribuição do material nas } \\
\text { escolas, em maio de } 2011 \text {. }\end{array}$ \\
\hline & $\begin{array}{l}\text { Diretrizes Nacionais para a Educação em Direitos } \\
\text { Humanos - referência a gênero e à orientação } \\
\text { sexual. Em 2012, obrigatoriedade da educação em } \\
\text { direitos humanos para o ensino médio e superior }\end{array}$ & $\begin{array}{l}\text { Valorização dos direitos humanos mediante temas relativos a gênero, } \\
\text { identidade de gênero, raça e etnia, religião, orientação sexual, pessoas } \\
\text { com deficiência, entre outros, e para construir práticas que promovessem } \\
\text { a igualdade e o enfrentamento de todas as formas de preconceito, } \\
\text { discriminação e violência. }\end{array}$ \\
\hline & $\begin{array}{l}\text { Aprovação da deliberação n. } 56 \text { na Conferência } \\
\text { Nacional de Educação (Conae), de 2014, para a } \\
\text { construção das Diretrizes Nacionais Curriculares } \\
\text { sobre Educação, Gênero e Diversidade Sexual para a } \\
\text { Educação Básica e o Ensino Superior }\end{array}$ & $\begin{array}{l}\text { Institucionalização e efetivação de uma política em educação e promoção da } \\
\text { equidade de gênero e de raça, bom como enfrentamento à homofobia. Foi } \\
\text { paralisado com o impeachment de Dilma Rousseff. }\end{array}$ \\
\hline & Plano Nacional da Educação (PNE) & $\begin{array}{l}\text { Previsão nos currículos da inserção de conteúdos de gênero, identidade de } \\
\text { gênero e orientação sexual, com o objetivo de superar as desigualdades } \\
\text { educacionais e as discriminações. Houve tensões e conflitos com forças } \\
\text { conservadoras que se articularam para a retirada desses termos, alegando } \\
\text { que era a implantação de uma "ideologia de gênero". }\end{array}$ \\
\hline & Programa Ciência Sem Fronteiras & Critério de seleção que dava prioridade para mulheres das áreas "hard". \\
\hline
\end{tabular}


de de gênero, colocando as mulheres como sujeitos do conhecimento, impactando, com isso, o campo da cultura, uma vez que determinadas representações das relações de gênero (Scott, 1990; Lauretis, 1994) atuaram como dispositivos de poder para excluir as mulheres nos espaços da produção dos saberes.

Aqui podemos incluir o Programa Ciências Sem Fronteiras, do governo Dilma, que, segundo Eleonora, era pautado pela transversalidade de gênero por priorizar a seleção de mulheres com projetos na área das ciências "hard". Assim, ao colocar critérios afirmativos que priorizem mulheres em áreas científicas, historicamente consideradas masculinas, observa-se o compromisso com políticas de equidade de gênero, para corrigir as lesões que a desigualdade produziu em relação às mulheres (Lagarde, 1996).

O segundo programa foi o de Gênero e Diversidades na Escola, que objetivava capacitar profissionais nos temas de gênero, raça e sexualidades, visando criar ambientes de convivência plural, de respeito às diferenças e da construção de uma cultura não homofóbica, não sexista e de igualdade de gênero. Foi um programa importante direcionado à mudança cultural a partir do espaço da educação e, apesar de ter atingido um número significativo de professores da rede de ensino público, não chegou a todos os profissionais, sobretudo nos lugares mais remotos. Nos últimos anos do governo Dilma, este programa foi tensionado pelas forças conservadoras, que nomearam a perspectiva de gênero de "ideologia de gênero".

12. Isso gerou certa insatisfação nas forças políticas do governo.

13. Vale recordar que isso tem relação com os resultados dos debates da Conferência Nacional de Ensino Médio (Coneb) e da Conferência Nacional de Educação (Conae), de 2010 realizada em 2008. O Documento da Coneb havia destacado uma educação com qualidade social voltada para a superação das desigualdades sociais, raciais, de gênero, de idade e de orientação sexual (Brasil, 2008).
Vale destacar que a hegemonia da noção denominada "ideologia de gênero" começa a se consolidar no Brasil justamente no primeiro ano do mandato de Dilma Rousseff, em 2011, quando o Supremo Tribunal Federal (STF) reconheceu a união entre pessoas do mesmo sexo. Nesse período, emergiu a polêmica em torno do material didático do Programa "Brasil sem Homofobia", nomeado pelos conservadores de "Kit gay", que seria distribuído nas escolas públicas e parte dele acabou sendo vetado pela presidenta, em maio de $2011^{12}$, após forte oposição das forças políticas e sociais conservadoras.

Entre as poucas iniciativas no campo das políticas educacionais com perspectiva de gênero, podemos destacar a homologação, em 2012, das Diretrizes Nacionais para a Educação em Direitos Humanos, que fazem referência ao gênero e à orientação sexual e enfatizam a necessidade de todas as pessoas usufruírem de uma educação não discriminatória e democrática, independente de sexo, orientação sexual, identidade de gênero etc. (Brasil, 2012a). Ainda, em 2012, as Diretrizes Curriculares Nacionais para o Ensino Médio estabeleceram a obrigatoriedade da educação em direitos humanos (Brasil, 2012b) ${ }^{13}$ e propôs que o Projeto Político-Pedagógico do Ensino Médio deveria acenar para a: 
XV. valorização e promoção dos direitos humanos mediante temas relativos a gênero, identidade de gênero, raça e etnia, religião, orientação sexual, pessoas com deficiência, entre outros, bem como práticas que contribuam para a igualdade e para o enfrentamento de todas as formas de preconceito, discriminação e violência (Brasil, 2012b: 7).

No entanto, esses temas geraram disputas políticas com a bancada religiosa reacionária, fundamentalista e conservadora e ganhou notoriedade no processo de aprovação do Plano Nacional de Educação (PNE) em 2013 e 2014. A polêmica foi gerada em relação ao artigo 2 o das diretrizes do PNE, especificamente em torno do inciso III, que tratava da superação das desigualdades educacionais, "com ênfase na promoção da igualdade racial, regional, de gênero e de orientação sexual." Tal concepção foi rechaçada e compreendida como implantação da "ideologia de gênero" nas escolas, de modo que as forças conservadoras conseguiram articular uma gramática política para a retirada dos termos gênero e orientação sexual do $\mathrm{PNE}^{14}$. O Plano foi aprovado com a redação "superação das desigualdades educacionais, com ênfase na promoção da cidadania e na erradicação de todas as formas de discriminação" (Brasil, 2014: 43).

Essa batalha se estendeu para dentro das câmaras estaduais e municipais, no processo da definição de seus respectivos planos de educação. Indubitavelmente, a ação das forças políticas conservadoras representou um retrocesso, por impedir avançar na construção de uma cultura pautada na igualdade de gênero, na superação da violência contra as mulheres e no respeito às diversidades sexuais.

Apesar das tensões e disputas em relação a gênero, o governo Dilma conseguiu manter a discussão em torno da Deliberação n. 56, aprovada na Conferência Nacional de Educação (Conae) de 2014, que estabelecia a construção das Diretrizes Nacionais Curriculares sobre Educação, Gênero e Diversidade Sexual para a Educação Básica e o Ensino Superior. De certo modo, isso foi uma conquista que resultou de alianças e esforço político que envolveu movimentos sociais de educação, LGBT e feministas. A construção dessas diretrizes visava institucionalizar e tornar efetiva uma política em educação, bem como promover a equidade de gênero e de raça e o enfrentamento da homofobia. Para esse fim, foram realizadas várias oficinas, cujos resultados foram sistematizados em uma carta que foi enviada ao presidente da Câmara de Educação Básica do Conselho Nacional de Educação (CNE), Luís Roberto Alves, o qual já havia se mostrado disposto a dialogar sobre a construção das diretrizes. Contudo, com o impeachment de Dilma Rousseff, o CNE foi recomposto em julho de 2016 e o professor Luís Roberto Alves foi afastado. Isso paralisou o processo já iniciado (Vianna et alii, 2016).
14. Toni Reis e Edla Eggert (2017) ressaltam que nenhum dos documentos finais das Conferências Nacionais de Educação, nem a versão inicial do PNE, se referem ao termo "ideologia de gênero" e sim objetivam alcançar a equidade de gênero e o respeito à diversidade sexual. 
15. Convém lembrar que a teoria de Butler traz uma contribuição original para pensar todas as classes de "corpos" cujas vidas não são consideradas "vidas" e cuja materialidade se entende como uma não matéria. Isto é, ela possibilita estudar os sujeitos "abjetos", que são excluídos de diversos espaços sociais, por não se adequarem às normas ou aos princípios hegemônicos, e a compreender seus processos de resistência e de agência que, partindo das "margens sociais", contribuem no processo de ressignificação de práticas sociais, colocando em cena cadeias reiterativas de outra ordem social.
Esse quadro evidencia que o Brasil teve um cenário político menos favorável que o Chile para implementar políticas educacionais com perspectivas de gênero, uma vez que gênero se tornou um campo de disputa na arena política. A linguagem sobre gênero e sexualidades tem sido um dispositivo com poder de articular regimes morais, políticos e formas de regulação da vida. A partir de 2010, a política foi marcada pelo adensamento de reações conservadoras articuladas com pautas ultraliberais, que protagonizaram o pânico moral em torno da categoria "gênero" e da diversidade sexual, atuando para impedir qualquer avanço em torno das políticas educacionais, apesar da vontade política do governo Dilma, da atuação do Feminismo de Estado e da pressão dos movimentos feministas e LGBT.

\section{Algumas considerações}

Conforme as evidências trazidas neste estudo, pode-se afirmar que as políticas transversais de gênero para a educação, que foram possíveis ser implementadas nos governos Dilma e Bachelet, em seus contextos específicos, contemplam os princípios de redistribuição e reconhecimento, segundo as concepções do paradigma de justiça social de Nancy Fraser (2002). Isso porque se criaram estratégias específicas para ampliar o acesso da população LGBT e das mulheres na educação, sobretudo nas áreas das ciências "hards", que, historicamente, foram consideradas espaços exclusivos dos sujeitos masculinos, brancos e heterossexuais. Embora, para Nancy Fraser as políticas de redistribuição estejam mais focadas aos bens econômicos, consideramos que o acesso à educação, sendo um bem simbólico, repercute diretamente na distribuição de renda e na reorganização da divisão do trabalho. Isso porque a educação pode ser um dispositivo de poder para as mulheres e as minorias sociais, no sentido de dar maiores possibilidades para a inserção no mercado de trabalho, melhorar salário e desenho profissional e, consequentemente, reduzir a pobreza, que, em geral, tem gênero, porque atinge mais as mulheres e também outras minorias sociais, com baixos níveis de escolarização.

No caso das diretrizes e normativas para a acolhida de crianças LGBTs, instituída no governo Bachelet, além de criar condições de acesso à educação, promove o respeito e a não discriminação por orientação sexual (política de reconhecimento), garantindo a permanência na escola de sujeitos culturalmente tratados como abjetos $^{15}$, na expressão utilizada por Judith Butler (2007). Ou seja, são vidas que não importam para um sistema heteronormativo e patriarcal e que acabam sendo excluídas de diversos espaços sociais, por não se adequarem às normas ou aos princípios hegemônicos. 
Para Fraser (2002), a justiça requer "redistribuição mais reconhecimento", em outras palavras, a justiça social evoca as exigências paralelas da igualdade e da diferença. Tereza Kleba Lisboa e Daniele Beatriz Manfrini (2005) recordam que fazer justiça não significa igualitarismo, e sim tratar os diferentes de maneira diferente. Pautadas nesse princípio, as políticas de discriminação positiva foram assumidas pelos governos do Chile e do Brasil, com o objetivo de favorecer as pessoas que por muito tempo ficaram em desvantagem em termos de direitos sociais e individuais que, nesse caso, são as mulheres e a população LGBT. Nesse sentido, considera-se que as políticas promovidas nos governos de Bachelet e Dilma são também políticas equitativas, à medida que visam construir a igualdade substancial, corrigindo desigualdades históricas, construídas sobre as diferenças dos corpos das minorias sociais.

As políticas públicas com perspectiva de gênero partem da premissa de que as instituições estatais participam da construção política e social das relações de gênero e, por isso, devem estar comprometidas a combater a iniquidade e a desigualdade entre homens e mulheres, em todas as áreas de ação do Estado e, aqui, o campo educacional é um dos espaços privilegiados para isso. Na concepção de Teresa de Lauretis (1994: 217), a "construção do gênero é produto e processo, tanto de representação quanto da autorrepresentação", de modo que gênero é definido como um conjunto de efeitos que são produzidos nos corpos por diferentes tecnologias de gênero, que podem ser discursos, práticas, arte etc. Desse modo, a instituição escolar é tanto um lugar de reprodução das desigualdades de gênero quanto de construção de novas relações.

Nesse sentido, compreende-se o empenho do governo Dilma e Bachelet em promover políticas educacionais, não somente para corrigir as desigualdades e desvantagens históricas em relação ao acesso à educação e ao reconhecimento das diferenças, mas políticas que impactem na cultura em vista de novas relações de gênero e de poder. E isso se evidencia nas iniciativas que incorporam conteúdos de gênero e de sexualidades na formação de professores, nas Diretrizes Curriculares e nas ações voltadas para a construção de uma cultura não homofóbica, não sexista e de igualdade de gênero. Tais políticas podem ser nomeadas de tecnologias de gênero, no sentido de Lauretis (1994), dado o seu poder de interferir na produção de novas relações.

Como pontuamos, é possível afirmar que Dilma e Bachelet deram prioridade para as políticas transversais de gênero na educação que, de certa forma, objetivavam atender as exigências dos organismos internacionais da ONU, sobretudo da Pla- 
16. Termo usado por Richard Miskolci e Maximiliano Campana (2017) para caracterizar os grupos que combatem o que denominam "ideologia de gênero". De acordo com esses autores, isso evita caracteriza esses grupos como uma espécie de movimento social, que seria supostamente alocado na sociedade civil. Aqui não está em questão quem são esses grupos, mas a análise de como eles se associam e se articulam, partindo do que Sonia E. Alvarez (2014) denomina de campos discursivos de ação, "nos quais preocupações político-culturais são compartilhadas mesmo que os atore nesses campos tenham diagnósticos divergentes" (Miskolci \& Campana, 2017: 730).

17. Vale recordar que o Partido Democrata Cristão, que integrava a Concertación de Partidos por la Democracia, depois da ditadura, sendo de perfil mais conservador, atuou para limitar avanços sobre os direitos sexuais reprodutivos, de modo que o Chile somente aprovou o aborto nas três causas - situação de perigo de vida da mãe, de inviabilidade fetal e por violação sexual, em 2017. taforma de Beijing e da Cedaw. Contudo, a possibilidade de se avançar ou não na implementação de certas políticas, está vinculada diretamente ao contexto cultural, social e político de cada país. São políticas de considerável importância para avançar na construção da igualdade de gênero, cujo processo parece se estagnar ou, até mesmo retroceder, com a ascensão de governos de direita no Chile e de ultradireita, no Brasil.

No Brasil, esse processo se apresenta mais desafiante, pois se visualiza um retrocesso no campo das políticas de gênero e fortes ameaças aos direitos conquistados. Vive-se de incertezas diante da atuação agressiva de grupos fundamentalistas e conservadores que se apresentam contrários aos direitos humanos na sociedade e junto às escolas públicas. Todo o processo feito em relação à construção das Diretrizes Nacionais Curriculares sobre Educação, Gênero e Diversidade Sexual para a Educação Básica e ensino Superior, virou uma espécie de lixo.

Se no governo de Lula houve avanços significativos nas políticas educacionais, desde a interseccionalidade de gênero, raça e orientação sexual, com ênfase na formação continuada dos profissionais da educação, o governo Dilma pretendia fortalecer e avançar ainda mais, sobretudo nas reformas curriculares. Contudo, sofreu forte oposição das forças conservadoras no Congresso Nacional que cresceram, consideravelmente, nas eleições de 2010 e se ampliaram ainda mais em 2014, barrando qualquer avanço significativo em relação às políticas de gênero, sobretudo no que diz respeito aos direitos sexuais e reprodutivos das mulheres e da população LGBT. Para isso se produziu um pânico moral em torno do que se chamou "ideologia de gênero", que foi protagonizado pelos empreendedores da moral ${ }^{16}$.

Esse contexto explica a especificidade do Brasil em relação ao Chile, quando observamos os avanços que foram realizados, sobretudo no segundo mandato de Bachelet. No Chile, algumas políticas foram possíveis porque o movimento contra o que se denominou "ideologia de gênero" não teve força. E, segundo os relatos das entrevistas, isso pode ser compreendido porque o catolicismo, que é a vertente religiosa predominante no Chile, nos últimos anos perdeu força política e credibilidade por ter importantes agentes religiosos envolvidos nas denúncias de pedofilia ${ }^{17}$.

Por fim, é importante sinalizar que, em um contexto de política neoliberal combinada com o neoconservadorismo, manter viva a reflexão sobre os avanços e os desafios em relação às políticas educacionais com perspectiva de gênero é uma estratégia política de fazer resistência diante do embate travado pelo que se chamou "ideologia de gênero" na educação, cuja ação discursiva tem interesses políticos de enfraquecer um projeto de sociedade pautada na igualdade de gênero e em valores democráticos. 
Nesse cenário, a crítica dos empreendedores da moral aos conteúdos de gênero e sexualidades na escola é uma questão política e não epistemológica ou teórica, de modo que gênero passou a ser um campo de disputa política, que põe em jogo um modelo de sociedade pautada na democracia e na igualdade de direitos. Novos cenários se evidenciam no campo da política, ou seja, há certo enfraquecimento das forças progressistas e do Feminismo de Estado e uma ampliação considerável das forças políticas conservadoras nas estruturas estatais e no poder legislativo, que agora passam a influenciar as ações estatais em outra direção, apoiadas em setores da sociedade civil. Isso evidencia como as decisões estatais sempre se definem com pressão e apoio de certos grupos da sociedade, que tem seus representantes no poder, como bem argumentou Eróstegui (2008).

Assim, o campo das políticas educacionais é um hoje um lugar de disputa, pois as forças políticas conservadoras têm tomado as ideias progressistas e transformado em projeto reacionário. Nesse sentido, Boaventura Santos, na conferência de abertura da XXXIX Reunião da Anped de 201918, argumentou que o desafio atual é transmitir o conhecimento científico e provocar nos estudantes a argumentação das ideias. Segundo ele, não se pode ser cúmplice das ideias conservadoras, pois se não nos opormos à chamada "ideologia de gênero" seremos cúmplices com a violência contra as mulheres, com as desigualdades e com todas as formas de discriminação de gênero.

\section{Referências}

ALVAREZ, Sonia E. Para além da sociedade civil: reflexões sobre o campo feminista. Cadernos Pagu, n. 43, p. 13-56, 2014.

ARRIAGADA, Irma. Cambios de las políticas sociales: políticas de género y família. Cepal-Série Políticas Sociales, n. 110, p. 1-39, 2006.

ASTELARRA, Judith. Veinte años de políticas de igualdad. Madrid: Ediciones Cátedra, 2005.

BADIE, Bertrand; HERMET, Guy. Política comparada. México: Fondo de Cultura Económica, 1993.

BANDEIRA, Lourdes M.; VIEIRA, Fernanda B. Brasil: fortalecimento da Secretaria Especial de Políticas para as Mulheres para avançar na transversalização da perspectiva de gênero nas políticas públicas. Brasília: Relatório de Pesquisa SPM/Cepal, 2004
18. Vídeo da conferência da abertura disponível em: <https://www. youtube.com/ watch?v= P4D75GOSMXg \&feature $=\mathrm{emb}$ $\log 0>$. 
BRASIL. Conselho Nacional de Educação. Parecer n. 8, de 06 de março de 2012. Aprova as diretrizes nacionais para a educação em direitos humanos. Diário Oficial da República Federativa do Brasil, Brasília: CNE, 2012a. Disponível em: <http://portal.mec.gov. $\mathrm{br} /$ index.php?option=com_docman\&view=download\&alias=10389-pcp008-12-pdf\&category_slug=marco-2012-pdf\&Itemid=30192>. Acesso em: 17 Fev. 2019.

BRASIL. Ministério da Educação. Conselho Nacional de Educação. Câmara de Educação Básica. Resolução n. 2, 30 de janeiro de 2012. Define diretrizes curriculares para o ensino médio. Brasília: MEC, 2012b. Disponível em: <http://webcache.googleusercontent.com/search?q=cache:C4yvCxwQEJ4J:portal.mec.gov.br/docman/ fevereiro-2012-pdf/9917-rceb002-12-1+\&cd=1\&hl=pt-BR\&ct=clnk\&gl=br>. Acesso em: 17 Fev. 2019.

BRASIL. Ministério da Educação. Conferência Nacional da Educação Básica. Documento Final. Brasília: Presidência da República; Ministério da Educação; Secretaria Executiva Adjunta; Comissão Organizadora da Conferência Nacional da Educação Básica, 2008.

BRASIL. Plano Nacional de Educação 2014-2024. Brasília: 2014. Disponível em: <http://www.proec.ufpr.br/download/extensao/2016/creditacao/PNE\%2020142024.pdf>. Acesso em: 13 Fev. 2019.

BUTLER, Judith. Corpos que pesam: sobre os limites discursivos do sexo. In: LOURO, Guacira Lopes (Org.). O corpo educado: pedagogias da sexualidade. 2. ed. Belo Horizonte: Autêntica, 2007.

CHILE. Ministerio de la mujer y la equidad de Género. Resultados medidas de la Agenda Género 2014-2018, 2018. Disponível em: <https://www.minmujeryeg.cl/ wp-content/uploads/2018/03/Resultados-Agenda-Ge\%CC\%81nero-2014-2018. pdf>. Acesso em: 12 Jan. 2019.

COMISSÃO ECONÔMICA PARA A AMÉRICA LATINA E O CARIBE (CEPAL). Informe anual 2011: O salto da autonomia. das margens ao centro. In: Comisión Económica para América Latina y el Caribe. Observatorio de Igualdad de Género de América Latina y el Caribe. Santiago: Nações Unidas, Set. 2011. Disponível em: <https:// www.cepal.org/publicaciones/xml/9/45929/OIG-Informe_anual__portugues.pdf>. Acesso em: 12 Jul. 2018.

ERÓSTEGUI, Susana. Sociedad civil, participación ciudadana y democracia en el nuevo contexto político de América Latina: una mirada a los desafíos y estrategias de acción desde la sociedad civil. Paper apresentado ao Seminário "Sociedad civil y nuevas institucionalidades democráticas en América Latina: dilemas y perspectivas". Brasília, 9 a 12 de novembro de 2008. 
FRASER, Nancy. Reframing justice. Amsterdam: Royal Van Gorcum, 2005.

. A justiça social na globalização: redistribuição, reconhecimento e participação. Revista Crítica de Ciências Sociais, v. 63, p. 7-20, Out. 2002.

FURLIN, Neiva. A relação entre Estado e sociedade no processo de institucionalização das políticas de gênero no Brasil e Chile. Revista Brasileira de Ciência Política, n. 32. p. 169-206, 2020.

GONZALEZ, Débora de Fina. Os mecanismos institucionais de políticas para as muIheres na América Latina: Arenas de/em disputas. Anais: International Congress of the Latin American Studies Association (Lasa), 36, 2018. Barcelona, ES, 2018.

Feminismos, Estado e políticas públicas: Brasil e Chile em Perspectiva. Anais: Seminário Internacional Fazendo Gênero, 11, \& Women's Worlds Congress, 13, 2017. Florianópolis, SC, 2017.

GUSMÁN, Virginia. Las institucionalidades de género en la región, documento borrador. In: Gobernabilidad, democracia y género, una articulación posible. Santiago, CL: Cepal, "Série Mujer y Desarrolho", n. 48, Out. 2005.

LAGARDE, Marcela. Gênero y feminismo: desarrollo humano y democracia. Madrid: Horas \& Horas, 1996.

LAURETIS, Teresa de. A tecnologia de gênero. In: HOLANDA, Eloísa Buarque de (Org.). Tendências e impasses: o feminismo como crítica da cultura. Rio de Janeiro: Rocco, 1994.

LISBOA. Tereza K.; MANFRINI, Daniele B. Cidadania e equidade de gênero: políticas públicas para mulheres excluídas de direitos mínimos. Katálylis, v. 8, n.1, p. 67-77, Jan./Jun. 2005.

LOVENDUSKI, Joni. State feminism and women's movements. West European PolitiCS, v. 31, n. 1-2, p. 169-194, Jan./Mar. 2008.

State feminism and political representation. New York: Cambridge University Press, 2005.

MATOS, Marlise; PARADIS, Clarisse G. Mulheres e políticas públicas na América Latina e Caribe: desafios à democracia na região. Encontro Anual da Anpocs, 37, 2013.

MISKOLCI, Richard; CAMPANA, Maximiliano. Ideologia de gênero: notas para a genealogia de um pânico moral contemporâneo. Sociedade e Estado, v. 32, n. 3, p. 725-747, Set./Dez. 2017. 
REIS, Toni; EGGERT, Edla. Ideologia de gênero: uma falácia construída sobre os planos de educação brasileiros. Educação e Sociedade, v. 38, n. 138, p. 9-26, Jan./Mar. 2017.

SALAZAR, Ana L. Flores. Políticas públicas de igualdad de género en Chile y Costa Rica. Um estudio comparado. Tese (Doctorado en Gobierno y Administración Pública) - Instituto Universitario de Investigación Ortega y Gasset, Universidad Complutense de Madrid, Madrid, 2015.

SCOTT, Joan W. Gênero: uma categoria útil de análise histórica. Educação e Realidade, v. 16, n. 2, p. 5-22, Jul./Dez. 1990.

STROMQUIST, Nelly P. Políticas públicas de Estado e equidade de gênero: perspectivas comparativas. Revista Brasileira de Educação, n. 1, p. 27-49, 1996.

VIANNA, Cláudia et alii. Gênero e educação: fortalecendo uma agenda para as políticas educacionais. São Paulo: Ação Educativa; Cladem; Ecos; Geledés; Fundação Carlos Chagas, 2016.

VIANNA, Claudia. Políticas de educação, gênero e diversidade sexual: breve história de lutas, danos e resistências. "Série Cadernos da Diversidade". Belo Horizonte: Autêntica Editora, 2018.

VIOTTI, Maria Luiza Ribeiro. Declaração e Plataforma de Ação da IV Conferência Mundial sobre a Mulher. Instrumentos internacionais de direitos das mulheres. Pequim, ONU-Mulheres, 1995. Disponível em: <https://www.onumulheres.org.br/ wp-content/uploads/2013/03/declaracao_beijing.pdf>. Acesso em: 17 Maio 2018. 